\title{
ARDUINO based accident prevention and auto intimation system
}

\author{
R.Palanisamy', PLS Sai Kumar ${ }^{2}$, Mekala Paavan Kiran³, Ashutosh Mahto ${ }^{4}$, Md.Irfan', \\ Maharishi Bhowmick ${ }^{6}$ \\ ${ }^{1}$ Assistant Professor, SRM Institute of Science and Technology, India. \\ 2,3,4,5,6UG Research Scholar, SRM Institute of Science and Technology, India
}

\begin{tabular}{|c|c|}
\hline Article Info & ABSTRACT \\
\hline Article history: & Often modern cars have a collision avoidance system built into them known \\
\hline Received Mar 10, 2019 & $\begin{array}{l}\text { as Pre-Crash System, or Collision Mitigation System in order to reduce the } \\
\text { collision. But maiority of vehicles on the road, especially heavy motor }\end{array}$ \\
\hline Revised Jul 11, 2019 & vehicles lack in such a system. In this paper, the implementation of the \\
\hline Accepted Aug 30, 2019 & $\begin{array}{l}\text { Collision Avoidance System is to reduce the risks of collisions at the hairpin } \\
\text { bend on a Hilly track, Ghats, or other Zero visibility turns. The proposed }\end{array}$ \\
\hline Keywords: & $\begin{array}{l}\text { system contains a set of IR sensors, LEDs, etc. It uses four IR sensors, } \\
\text { which are placed on either side of the hairpin bend. The sensors are mutually }\end{array}$ \\
\hline ARDUINO & exclusive and are connected to LEDs through wires. Based on the output of \\
\hline Arduino UNO & $\begin{array}{l}\text { sensors, the the ond Hence the drivers will decrease their speeds which would } \\
\text { from the the }\end{array}$ \\
\hline GSM module & help in preventing collision. The LEDs will help the drivers in detecting the \\
\hline IR sensor & position of the vehicles on either side of the bend. During climatic conditions \\
\hline RFID system & $\begin{array}{l}\text { like fog, snow, etc, the visibility of the drivers would decrease due to which } \\
\text { they will not be able to see the LEDs, Hence, a collision may take place. } \\
\text { To bring help as soon as possible to the injured, we have also made a } \\
\text { proposed system which would alert the nearby hospitals that an accident has } \\
\text { taken place. We have used Arduino UNO, GSM sim module and these will } \\
\text { be kept inside a black box which will be inside the, car safe from breakage } \\
\text { during the accident. }\end{array}$ \\
\hline
\end{tabular}

Copyright $(2020$ Institute of Advanced Engineering and Science. All rights reserved.

\section{Corresponding Author:}

R. Palanisamy,

Asst. prof, Department of EEE,

SRM Institute of Science and Technology,

Chennai, India.

Email: krspalani@gmail.com

\section{INTRODUCTION}

A rapid growth in transportation and vehicles has resulted in an increase of accidents everyday mainly due to the driver's carelessness or due to bad traffic control. According to a survey, crashes on curved roads have $10 \%$ of total number of traffic crashes. In narrow curved roads in Ghat sections, driving is not an easy task [1]. They have to be alert all the time while driving in such roads. Hence, we have developed a model by which drivers can properly take turns in these kind of roads without any accident taking place.

Currently the following methods are being used, Convex mirrors were placed at point of the bend in the road so that the driver could see whether any other vehicle is coming from the other end or not. After seeing the other vehicle, the drivers would decrease their speed and pass each other without any accident taking place. These mirrors are larger in size so that the drivers could see the type of vehicle coming from the other end and decrease their speeds eventually. Another way could be by using vehicle horns. The drivers on both sides judge the distance of one another by honking their horns and the intensities of sound from their respective horns [2]. 
The setup of placing convex mirrors to give a glimpse of any vehicle approaching from the other end has its own drawbacks. The mirror needs to be cleaned at all times which is difficult in Ghat sections as it is always dusty and misty, thereby reducing visibility. Due to climatic conditions like fog, snow etc., and the mirror could be out of visibility range for the driver and could lead to an accident. Using vehicle horns, although being the simplest, it can be highly inefficient. Due to the sound it could cause a lot of confusion between the drivers.

As we are using IR Sensors in our project, some of the other methods could be by using Metal detectors at each end of the curve, placing sensors inside bumpers made at each end. The metal detectors will detect any metallic object passing through it and immediately warn the driver on each ends by giving a sound or by using traffic lights. We can also make bumpers at each end and place sensors inside them so that if any vehicle tends to pass over them it would signal the other car approaching and then the drivers would make the turn by decreasing their speed eventually.

Life is precious. It is a gift given by god. We should not loose our life for small reasons. In our country more than $50 \%$ of its population is below the age of 25 and more than $65 \%$ below the age of 35 [3]. It is a good sign to our country to become one of the super power countries. But most of the youngsters are losing their life in road accidents. According to the road statistics in India over 1,37,000 people were killed in killed in 2013 alone which is more than the number of people killed in all our wars [4]. 16 children die in our country daily due to accidents. For every four minute there is one death in our country due to road accidents. 1214 road accidents occur daily in our country. It not only hurt the parents but the GDP of our country. Due to road accidents our country is losing 3\% GDP. Tamilnadu is the state with maximum number road crash injuries every year. It's been in top 5 every year in road crashes. "Many road accidents are the result of faulty road design and enginnering.The road, especially a single-lane one with a sharp curve poses a big danger. It should design in a way that one can see the vehicle coming from other side."Adds Amar Srivastava, Founder, Indian Road Safety Campaign [5].

\section{PROPOSED SYSTEM CONCEPT}

In Figure 1 the block diagram shows the proposed system for the prevention of road accidents. This system has a 9v battery as a source, a set of IR sensors, LED lights combined with Buzzers to make sound and these are installed on the side of the road. It uses two IR sensors, which are placed on the ends of the bend road. The distance between the vehicle and the sensor will be 3 to $4 \mathrm{~cm}$. Each sensor is connected with buzzers and is mutually exclusive.

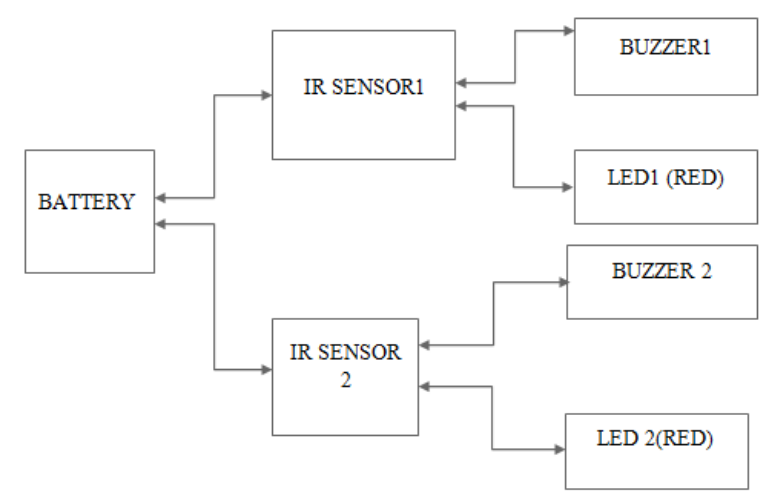

Figure 1. Proposed system block diagram

\subsection{Interfacing GSM Module to Arduino to Give Intimation}

In Figure 2 shows the block diagram shows the interfacing of GSM module to arduino to give message after proposed system. We will give coding in the Arduino which will contain the number of the receiver who will get the message from the car that has been in the accident. It will send information to the GSM module. We have placed a $2 \mathrm{G}$ sim inside the module. When the information is received from the arduino it will analyse it and then send a message on the number given in the coding. After getting the message, the hospital will send an ambulance to the location from where the message came. 


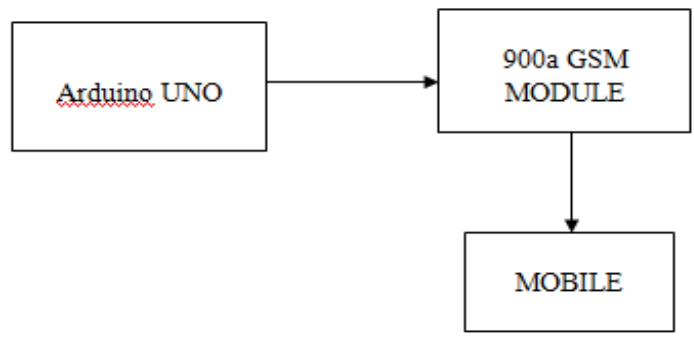

Figure 2. Interfacing GSM module to give message after proposed system

In this project we are using GSM sim900 because in our country most of the mobile networks work in $900 \mathrm{Mhz}$ band. GSM sim900 supports communication in 900 Mhzband.GSM sim900 is manufactured by SIMcom Company.

\subsection{Working of Proposed System}

We have made a system which contains a set of IR sensors, LED lights combined with Buzzers to make sound when any vehicle crosses the IR sensors and these are installed on the side of the road. It uses two IR sensors, which are on either side of the hairpin bend. The sensors are mutually exclusive. Based on the output of sensors, position of vehicles on either side of the bend is detected with the help of LEDs. For different conditions appropriate LED is triggered thereby prioritizing the vehicles' movement.

Even after all the warnings if any accident occurs, inside the car, a End-switch will be present which will be placed right inside the car bumper. When the other car hits the bumper the switch will be on and it will send information to the Arduino. A coding will be given to the Arduino which will contain the number of the receiver. From there it will send information to the GSM Module and from there it will send the message to the number given in the coding. As soon as the message is sent to the nearby Hospital, an Ambulance will be the sent to the location from where the message was sent and this is how the injured person will be saved without any loss of life.

Booting the GSM Module: Before starting of the project we have to boot the GSM module. We have to insert the sim card and lock it. Connect the adapter to GSM module and make it on. We have to wait to witness the blinking rate of status led. Once the connection is established successfully, led will blink continuously every 3 seconds. To further make it confirm whether the connection is established or not we can make a call to the mobile number of the sim card inside GSM module if we hear a ring back, the GSM module has successfully installed. Connecting GSM module to Arduino-There are two ways of connecting GSM module to Arduino. First method-Connecting Rx, Tx pins of Arduino to GSM module of Tx \& Rx pins respectively, GND pin of Arduino to GND pin of GSM module.

Second Method-We can make use of digital pins 9,10 of Arduino as Rx, Tx pins. But we will prefer Second Method because every time when we have to burn the program from Arduino we have to remove Rx, Tx pins, so it is difficult.

\section{CONTROL STRATEGY}

\subsection{Coding}

The baud rate is the rate at which information is transferred in a communication channel. In the serial port context, "9600 baud" means that the serial port is capable of transferring a maximum of 9600 bits per second.

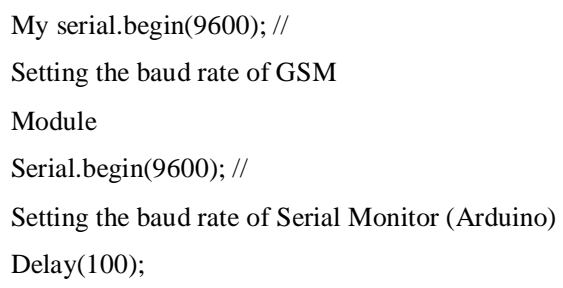

Code 1. Setting baud rate 
After setting the baud rate we check whether the sim is sending or receiving messages. For that we can call on the number of the sim which we have given in the module, if we hear a ring back then module has successfully installed.

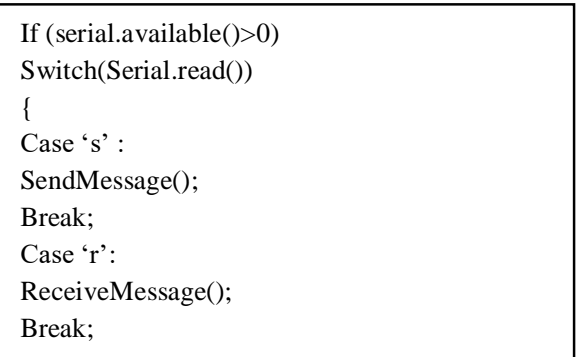

Code 2. Send and receive messages

We give the receivers number in the coding. A message will be sent to that number after a certain period of time indicating that an accident took place. The time period will be given in the coding.

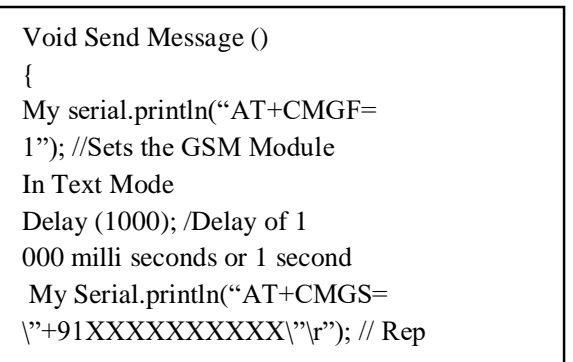

Code 3. Message sent to receiver

The SMS sent will have the given information, "we met with an accident, please come and help us and call 91xxxxxxxxxx".

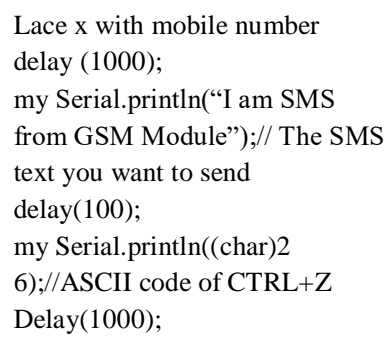

Code 4. SMS text

\section{EXPERIMENTAL RESULTS AND DISCUSSIONS}

\subsection{Components Used and Its Ratings}

Connecting Rx, Tx pins of Arduino to gsm module of Tx\&Rx pins respectively, GND pin of Arduino to GND pin of GSM module shown in Figure 3. We can make use of digital pins 9,10 of Arduino as $\mathrm{Rx}$, Tx pins. We are putting an obstacle infront of the sensor and then we see the LED which is placed in the 
criss cross manner to the sensor will start glowing with red color indicating the the other car approaching to decrease its speed shown in Figure 4 and 5.
1. GSM Sim 900a
2. $2 \mathrm{~g}$ Sim Card
3. Arduino UNO
4. Jumper Wires
5. Adapter (12v-2amp)
6. End switch
7. IR Sensors
8. LEDs
9. Batteries $(9 \mathrm{~V})$
10. Resistors
11. Voltage Regulators

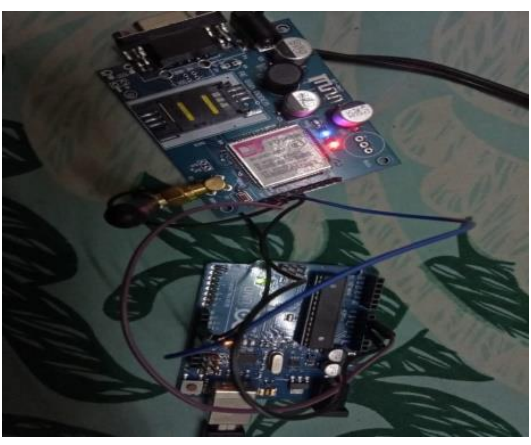

Figure 3. Experimental setup

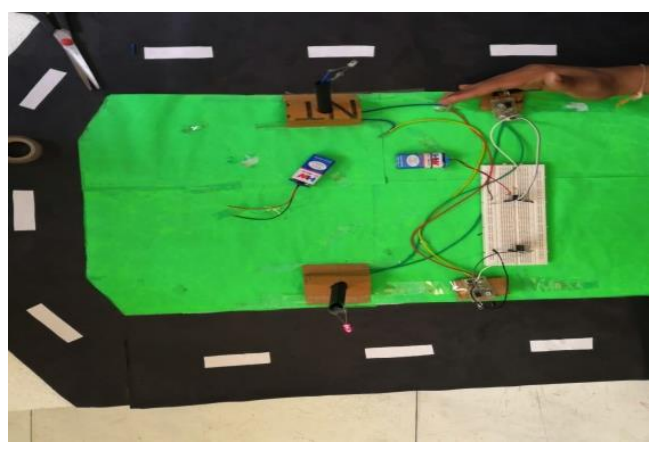

Figure 4. Different conditions whether the car is approaching from left or right

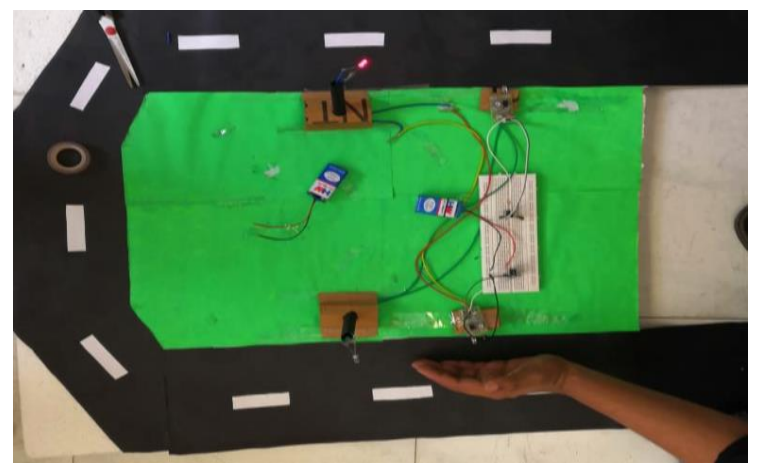

Figure 5. RFID using accident prevention system

\section{CONCLUSION}

Our Collision Avoidance System consisting of IR sensors, warning LEDs and when implemented has proven to be more effective than just a normal traffic mirror setup. The system, as shown in the results, has performed accurately under various conditions prioritizing the vehicles negotiating a hairpin bend on a Hilly track, Ghats etc. This simple yet effective methodology will enable the driver to have a better sense of terrain and will drastically reduce road accidents in hairpin bends or other kinds of zero visibility turns.

\section{REFERENCES}

[1] R. S. Rakul S. Ravia K. N. Thirukkuralkani, "Implementation Of Vehicle Mishap Averting System Using Arduino Microcontroller", International Journal of Engineering Research \& Technology, Vol. 5 Issue 04, April-2016.

[2] Jessen Joseph Leo, R. Monishaz, "Vehicle Movement Control Andaccident Avoidance In Hilly Track”, International Conference on Electronics and Communication System JCECS -2014. 
[3] EiEi Thwe, Theingi, "Design And Implementation Of Data Logger For Vehicle Safety", International Journal of Engineering and Techniques - Volume 1 Issue 4, July - Aug 2015.

[4] D. Haripriya, Puthanial. M, Dr. P. C. Kishore Raja, "Accident Prevention System And Security For Vehicles", International Journal of Computer Trends and Technology (IJCTT) - volume 12 number 5 - Jun 2014

[5] Liang Qi, MengChu Zhou, WenJing Luan, "Emergency Traffic-Light Control System Design For Intersections Subject To Accidents", IEEE transactions on Intelligent Transportation Systems, vol. 17, no. 1, January 2016.

[6] C. Thompson, J. White, B. Dougherty, A. Albright, and D. C. Schmidt, "Using Smart phones to Detect Car Accidents and Provide Situational Awareness to Emergency Responders," in 3rd International ICST Conference on MOBILe Wireless MiddleWARE, Operating Systems, and Applications (Mobilware 2010), 2010.

[7] D. A. Whitney and J. J. Pisano TASC, Inc., Reading, Massachusetts, "Auto Alert: Automated Acoustic Detection of Incidents", IDEA project, [Online]. Accessed on 15 October 2011, Available: http://pubsindex.trb.org/view.aspx?id=481489.

[8] L. Chuan-zhi, H. Ru-fu, Y.E. Hong-wu, "Method of Freeway Incident Detection Using wireless Positioning," in Proceedings of the IEEE International Conference on Automation and Logistics, 2010, pp. 2801 - 2804.

[9] S.George Fernandez, R. Palanisamy, K. Vijayakumar, "GPS \& GSM Based Accident Detection And Auto Intimation" Indonesian Journal of Electrical Engineering and Computer Science (IJEECS), Vol. 11, No. 1, July 2018, pp. 336 361.

[10] R. Elvik, P. Christensen, A. Amundsen, "Speed and road accidents: an evaluation of the Power Model," TOI Report, [Online]. Accessed on 12 October 2011. Available: http://www.trg.dk/elvik/740-2004.

[11] R. K. Megalingam, R. N. Nair and S. M. Prakhya, “Wireless Vehicular Accident Detection and Reporting System,” in International Conference on Mechanical and Electrical Technology (ICMET 2010), 2010, pp. 636-640.

[12] Speed and Accident Risk, Europian Commision Road Safety, [Online] Accessed on 07 October -2011.

[13] A. Di Febbraro, D. Giglio, and N. Sacco, "On using Petri nets for representing and controlling signalized urban areas: new model and results, " in Proc. IEEE ITSC'09, 2009, pp.771-778.

[14] A. Di Febbraro and D. Giglio, "On representing signalized urban areas by means of deterministic-timed Petri nets, " in Proc. IEEE ITSC’04, 2004, pp. 372-377.

[15] A. Di Febbraro, D. Giglio, and N. Sacco, "On applying Petri nets to determine optimal offsets for coordinated traffic light timings, ” in Proc. IEEE ITSC'02, 2002, pp. 773-778.

[16] A. Di Febbraro, D. Giglio, and N. Sacco, "Modular representation of urban traffic systems based on hybrid petri nets, ” in Proc. IEEE ITSC'01, 2001, pp. 867-872.

[17] G. Ciardo and C. Lindemann, "Analysis of deterministic and stochastic Petri nets," in Proc. IEEE 5th Int. Workshop, Oct. 1993, pp. 160-169.

[18] M. A. Marsan and G. Chiola, "On Petri nets with deterministic and exponentially distributed firing times," in Advances in Petri Nets 1987. Berlin, Germany: Springer-Verlag, 1987, pp. 146-161.

[19] A. Zimmermann, M. Knoke, A. Huck, and G. Hommel, "Towards version 4.0 of TimeNET," in Proc. 13th GI/ITG Conf. Meas., Modeling Eval. Comput. Commun. Syst., 2006, pp. 477-480.

[20] H. A. P. Blom, J. Krystul, G. J. Bakker, M. B. Klompstra, and B. Klein Obbink, "Free flight collision risk estimation by sequential Monte Carlo simulation," in Stochastic Hybrid Systems; Recent Developments and Research Trends, C. G. Cassandras and J. Lygeros, Eds. New York: Taylor \& Francis, 2007.

[21] M. Ghazel, "Using stochastic Petri nets for level-crossing collision risk assessment," IEEE Trans. Intell. Transp. Syst., vol. 10, no. 4, pp. 668-677, 2009. 